\title{
De la igualdad constitucional (I PARTE)
}

- Salvador Héctor Soriano Rodriguez

\section{Consideraciones introductorias}

\section{Valoraciones generales}

La igualdad como principio jurídico requiere circunstancias especiales de valoración. Precisa equilibrar las desventajas de los que están en posiciones desfavorables e imponc un equilibrio cuando los sujetos están en posiciones de igualdad horizontal. Las situaciones valorativas de la jurisprudencia constitucional han puesto en el punto decisivo de la discusión el trabajo nocturno de las mujeres. Se han considerado las circunstancias que han permitido que la mujer sufra más que el hombre, los riesgos en los centros de trabajo y la doble jornada —doméstica y laboral- - La igualdad ha dado luz verde al reclamo del derecho de mujeres que sean asistidas por mujeres en sus partos. Por otra parte, se ha considerado la prohibición de la plaza de vigilante masculino para prisiones de mujeres. También se ha considerado la opción del trabajo de mujeres en las minas. Se ha logrado la incorporación de las mujeres en las Fuerzas Armadas de varios países. Asimismo, se cuentan innumerables ejemplos en lo que respecta a las valoraciones de igualdad: las reservas de cuotas laborales por razón de minusvalías, plazas electorales femeninas, el favorecimiento para personas desempleadas y reducciones de salarios para las ya incorporadas. En definitiva, la igualdad no sólo es una pretensión económica - entendida como distribución equitativa de bienes materiales-, sino también un equilibrio de opciones, oportunidades, promociones, accesos, tratamientos y de diferencias que no partan de criterios arbitrarios para establecer distintos niveles de beneficios para los individuos y colectivos.

De la lgualdad consiltuclonal ( PARIE) 


\section{Antecedentes básicos}

\subsection{Visión clásica}

Un enfoque clásico aparece en Burgoa, que inicia en la Antigüedad un recorrido por las instituciones que han sancionado negativamente la igualdad. Hoy en día se considera pervertida la institución de la esclavitud, que concibió a los seres humanos como objetos de contratación. Para Zarini, la esclavitud está reñida con los principios elementales de humanismo. También priva a las personas de la esfera de libertad necesaria para desarrollar la personalidad, somete a los hombres al dominio de otros hombres y considera a los esclavos como cosas'. Las diferencias romanas entre patricios y plebeyos, romanos y extranjeros no fueron situaciones jurídicas extrañas. Las distinciones, sin embargo, igualaron por medio del ius gentium la humanidad de las personas, sentido que supeditó la contrariedad al derecho natural que legitimaba la esclavitud².

La Edad Media supeditó los siervos al señor feudal. Especial consideración recibe la valoración de la igualdad desde la doctrina cristiana. Sus postulados parten de planteamientos moralistas - la purificación, la elevación de las conciencias - para concebir el régimen servil como una ocasión para ejercer las virtudes de la paciencia y la obediencia, poner de manifiesto la dulzura de los amos y la mitigación de las diferencias con la caridad.

La cristiandad se sume así en una especie de cataclismo con la patrística?, movimiento que escinde lo terenal, caduco y temporal de lo eterno, divino y celestial. El Estado terrenal, instrumento de fines temporales, se dirige a su desaparición para restableer el Reino de Dios. La cristiandad se moviliza también con la escolástica ${ }^{4}$, escuela de una partición tripartita de la ley: eterna, natural y humana. La igualdad se presenta en la obligación del Estado de realizar el bien común y de encaminarse al Reino de Dios, a lo que no deben resistirse los soberanos terrenales. El hombre es libre, según esta concepción, en la medida que se subordina al poder eclesiástico.

Los escritores gibelinos y los doctrinarios contractualistas elaboran una doctrina de notoria importancia en la Edad Media. El poeta Dante Alighieri preconiza la unidad política, la soberanía del Emperador, así como la independencia y superioridad de éste sobre el poder de la Iglesia. Tendencias análogas aparecen en Ludovico El Bárbaro, que fundamenta el poder político en el pueblo, las obligaciones del Príncipe para con este y el deber del monarca de observar la ley. Marcilio

1. Helio Juan Zarini, Derecho Constitucional. Astrea-Depalma, Buenos Aires, ${ }^{\circ}$ edición, 1992, Pág. 386.

2. Giorgio del Vecchio, Filosofía del Derecho. Bosch-Barcelona. IX Edición, 1991. pág. 25.

3. Ibidem, pp. 28 y ss.

4. Ibidem, pp. 30 y ss

\section{8}

Realldad 80, 2001 
de Padua estructura una teoría contractualista. De forma paralela, se elaboran doctrinas contractuales de diferente tipo. La igualdad se presenta, entonces, como la necesidad de que exista un Estado que obligue a los hombres a respetarse y a vivir en paz. Los individuos se subordinan a un gobierno lormado sobre la base del contrato social'.

Las dimensiones que aporta al espíritu humano el Renacimiento autonomizan la igualdad como género: espíritu y sujeto que independizan a la persona. Aquí, la libertad es igualdad: Libertad para todos. La igualdad se manifiesta también en distinciones libertarias de diverso tipo. Un ejemplo de encumbrada incidencia es la libertad religiosa que se deriva de la reforma religiosa. La igualdad se complementa con las grandes mutaciones políticas, en que las pequeñas potencias disgregadas lorman Estados independientes del Papado y el Imperio". Resulta una igualdad de libertades que se absolutizan en la fuerza monopólica y unitaria del Estado.

La Edad Moderna inicia con las ideas dominantes de Maquiavelo. Este autor (logmatiza consejos para una unificación patria, con el lïn en que predomine Italia y gobierne mediante un Estado unitario. Bodin contribuye con las afirmaciones de un Estado que posea un poder supremo y soberano. Dicha concepción comprende las facultades de hacer leyes y una situación jurídica en que el pueblo tiene sólo deberes, pero no derechos. Otros aportes a la Modernidad serán dados también por Grocio, Campanella y Descartes. La igualdad es el reconocimiento de una misma razón humana, la determinación de relaciones iguales entre los Estados y cl establecimiento de prácticas que eviten la guerra y asienten la paz. Más adelante, surgen las doctrinas que formula Hobbes sobre el egoísmo de los seres humanos. En este sentido, guarda similitudes con Spinoza. La modernidad se caracteriza también por la igualdad en el derecho a la libertad, planteamiento que se recoge en las doctrinas de Locke y de Rousseau?

Li Modernidad tiene un grave sobresalto en la Europa continental, con la Revolución Francesa, que elevó la igualdad a la categoría de derecho individual ${ }^{*}$. La Revolución Francesa deposita la igualdad en la era de los revolucionarios liberales. Surge entonces el lema de un Estado que purifica la igualdad en las formalidacles: depositi la identidad en los destinatarios de la ley, así como sus electos y consecuencias. El cambio obedece al hecho de que en las sociedades basadas en cstamentos, la igualdad se ampara en la pluralidad de ordenamientos y posiciones jurídicas, que condicionan la aplicación de la ley en virtud de la posición que ocupa el individuo en la sociedad. Se trata de acabar con la fragmentación del

5. Hiclem. pp. 34 y ss.

6. Midem. pp. 30 y ss.

7. Ihidem, pp. 428 y ss.

8. Ignacio Burgoal, Las garantías individuales. Porrúa, México. 5ª edición, 1968, pág. 2.59 y ss.

De la igualdad constilucional (I parte) 
orden jurídico, y finaliza consiguiendo la igualdad en los alcances generales de la ley para los destinatarios. En principio, prohibe regulaciones singulares. Más adelante, veremos las posibilidades permitidas en la singularidad normativa".

Se pueden notar regulaciones de avanzada histórica en los antecedentes de la igualdad en la Declaración de Virginia, de 1776, la cual reconoce independientes e igualmente libres a todos los hombres por su naturaleza. La Declaración de los Derechos del Hombre y del Ciudadano, de 1789, consagra la libertad e igualdad de los hombres. Sin embargo, en un apartado establece restricciones para ostentar dignidades, ocupar cargos y desempeñar empleos por criterios de capacidad, talento y virtudes ${ }^{(1)}$. También concibe la contribución físcal a los gastos de la Administración y la Fuerza Pública como algo que debe regirse por criterios de posibilidades económicas". Cabe afirmar que, en términos generales, la igualdad ha dado dos saltos cualitativos: Primero, de las formas pasa a la materialidad. Segundo, de los hechos ordenados en una norma objetiva pasa a subjetivarse en los hechos reales como contenido material. El impulso se debe a las modificaciones en las organizaciones políticas. Se pasa del Estado individualista al Estado social que colectiviza derechos sociales para bienestar de algunos desaventajados.

\subsection{Enfoque contemporáneo}

La contemporaneidad de la igualdad experimenta transformaciones que superan las formalidades y se adentran en el campo material. La modificación de concepción comienza en las materias tributarias. El principio de progresividad de los tributos hace la equiparación del sacrificio económico en proporción ${ }^{12}$ a los bienes del contribuyente; y se plantea en el constitucionalismo por medio de

9. Luis López Guerra y otros, Derecho Constitucional. El ordenamiento constitucional y deberes de los ciudadanos. Volumen I. Tirant Lo Blanc, Valencia, 1994. I edición. pág. 160

10. La evolución de este precepto puede notarse en el Art. 219 de nuestra Constitución, en el que, al establecer la carrera administrativa, prescribe una reserva de ley para la regulación del servicio civil, que contempla requisitos basados en el mérito y la cipritud para acceder a promociones y ascensos.

11. Francisco Bertrand Galindo, Albino Tinetti y oros. Manual de Derecho Constitucional, Tomo II. Centro de Información Jurídica, Ministerio de Justicia, San Salvador, 1996. I Edición. Pág. 796.

12. La proporcionalidad en las diferencias de trato mide las consecuencias entre las situaciones de hecho y la linalidad perseguida con la distinción. Los sujetos deben estar en situaciones distintas de hecho; la diferencia debe tener una finalidad razonable. admisible por los principios, valores y normas constitucionales; la difcrencia debe ser coherente: y las consecuencias jurídicas de la distinción no deben ser desproporcionadas. Cir. Luis López Guerra y otros. Derecho Constitucional. El ordenamiento constitucional y cleberes de los ciudadanos, pág. 169 
la idea de la compensación. Se supera la igualdad ante la ley y se admite la igualdad material. Se suscita una ruptura parcial de la universalidad, generalidad, abstracción y duración de la ley, con la admisión de leyes singulares. Éstas son particularizaciones que se destinan en la singularidad para los individuos y los colectivos. En tales particularizaciones, las normas jurídicas temporalizan la coactividad de sus supuestos; incluso, a veces, dicha transitoriedad se obvia. Como consecuencia de esto último, las leyes permanentes diferencian tratamientos por las características de las situaciones reales de sus destinatarios. Por otra parte, se constata que la novedad de una igualdad material obliga a los poderes públicos para que sea real y efectiva!?.

Las proyecciones jurídicas de la igualdad pasan a ser una noción más compleja que las prédicas liberales de formalidad. La igualdad limita a los poderes públicos y reacciona ante las arbitrariedades bajo la política de principios negativos y limitadores. Este punto de vista impulsa la igualdad axiológica, promocional y comporta interdicciones de la arbitrariedad. Así, pierde el sentido único de lormalidad y se complementa en la perspectiva material' ${ }^{14}$.

La Constitución de la India, bajo la denominación de la política de reservas, constituyó un mandato de reservar puestos en la Administración del Estado a los miembros de una casta - los intocables- En los años setenta y ochenta, la utilización de la igualdad lleva una política de integración de las mujeres, las minorías raciales y lingüísticas.

Lil lengua ha enlirentado decisiones judiciales. Una sentencia del Tribunal Supremo Español, Cuarta Sección de la Sala Tercera, considera que no se infringe la igualdad al exigir el conocimiento de eusquera en la selección de personal de un ayuntamiento del País Vasco, para cubrir plazas directamente relacionadas con la utilización de la lengua por la Administración. Derivaría en inliracción si no hubiese conexión con pucsios o funciones que no requieren del conocimiento lingüístico cspccial. El mencionado tribunal, en la sentencia del 14 de octubre de 1998 , añade que el derecho de ser atendido en castellano no se afecta por el acuerdo del pleno de un Ayuntamiento que declara el vivir y luncionar en eusquera. No se clecluce la exclusión del castellano, ni el uso único y obligatorio del eusquera.

\section{Estado e igualdad}

\subsection{Ideas plurales}

Las formalizacioncs de la igualdad atañen indudablemente al modo en que los ciudadanos se organizan políticamente. La csencia del planteamiento está en

13. Luis Lope. Guerra y otros. Op.cit., p. 160.

14. Ihickem, p.16I.

De la igualdad constitucional (I PARE) 
la tipología de los Estados. La organización dominante en Occidente es el Estado Social. Nos referiremos a diferentes doctrinas que lo justifican en la perspectiva de la igualdad.

Para Maritain, las democracias modernas desarrollan la justicia social y equipan al pueblo para el ejercicio de la libertad junto al bien común. El prestigio y la dignidad recuperan la idea de la justicia. Pelayo incluye la corrección de la igualdad para las faltas de equidad, los requisitos para la existencia mínima, la participación en el producto social, así como la distribución y prestaciones sociales a las que acceden las masas por consumo dinámico, lo cual equilibra los valores dinámicos del Estado. Por su parte, Enterría aprecia la igualdad en fines de fomento, bienestar y felicidad e incorpora la transformación de condiciones. El humanista Rousseau conviene en la conversión social del hombre. La riqueza, el rango, la nobleza, el poder y los méritos, son los criterios para considerar el bien o el mal del Estado. En el planteamiento del autor del Emilio, se evita las cargas sobre los otros y se eclipsa el yo. La democracia repara las desigualdades y modifica los resultados de la envidia, ira y odio. Todos los grupos deben estar representados sin que ello implique individualidad. Una de las preocupaciones principales cs la de reparar las desigualdades producidas por el grado de riqueza ${ }^{15}$.

Tocqueville, a su vez, estudia la situación de América y encuentra el fundamento en la igualdad. Constituye una sorpresa para este autor la igualdad de condiciones, más allá de las costumbres, la política y las leyes. La igualdad, según la estudió Tocqueville, permite en el gobernado la creación de opiniones, usos y modifica lo no productivo. Para este autor, la igualdad es un hecho providencial, universal y durable, que sirve al desarrollo de los hombres en igualdad de condiciones. La igualdad es, pues, un fin del Estado.

Finalmente, Myrdal entiende la igualdad como consagración de la democratización cle los procesos políticos, como conciencia del poder y como forma de presión hacia una distribución equitativa ${ }^{16}$.

\subsection{Igualdad y absolutismo}

La macroorganización política de la igualdad ha sido diseñada en la historia por los Estados liberales. Antes del liberalismo, la igualdad se mide bajo el rasero del absolutismo de los Estados, que penden de un poder único y personal, asentado en el monarca. El Rey es juez, ejecutor de las leyes y entidad jurisdic-

15. Fernando Díez Moreno, El Estado Social y la desigualdad, en XI jornadas de estudio: El principio de igualdad en la Constitución española, volumen I, Dirección General del Servicio Jurídico del Estado. Centro de Publicaciones de la Secretaría Gencral Técnica del Ministerio de Justicia, 1991. Pág. 87 y ss.

16. Díc\% Moreno, Op. cilt., pág. 87 y ss. 
cional. Es importante destacar el hecho de que estas son características de los Estados de la Europa continental. El absolutismo es menos riguroso en las islas británicas. El monarca es obligado pacíficamente a perder la centralización del monopolio de las funciones gubernativas. Esta es una pérdida del poder, de las facultades y potestades absolutas, sin que ello comporte grandes impactos sociales. La erosión del poder absoluto se produce en un marco gradual, sin sobresaltos que impliquen choques de trascendental e imperiosa distorsión del sistema político adoptado. Esto resulta distinto a los impactos que se registran en las funciones estatales monopolizadas de los Estados del continente. La igualdad en este estadio, es la igualdad individual, que no reparte beneficios para nadie, sino sólo para el Rey. La igualdad es libertad; ésta, a su vez, es la igualdad de un monarca comparada con el rey. El Rey puede ser igual sólo consigo mismo. La igualdad es una fantasmagoría que cobra su fuerza en un solo individuo que detenta el poder y no representa ningún término de comparación respecto de los demás.

El absolutismo estatal sirve a las tareas económicas, necesitadas de leyes uniformes y distribuidas en funciones de creación, ejecución y aplicación normativa - es la idea de la separación de poderes-. Es en ese momento en que el absolutismo pierde sentido. Luego de crear la uniformidad de regulación y después de marcar territorios, sus utilidades políticas de poder dejan de tener sentido. Ha sido solamente un estadio que canaliza la plataforma de configuración clel Estado de Derecho liberal. El absolutismo no es otra cosa que un modelo de organización política que se ve transformado por el papel rector del liberalismo. En éste último, el gobierno adopla una mínima intervención y deja las libertades a la iniciativa creadora de los particulares, todo ello con el fin de que las inicialivas privadas desarrollen una era industrial y devengan en una época de invenIos, proporcionando mejores condiciones de vida en la comunidad.

\subsection{Igualdad liberal}

El liberalismo aporta la igualdad formal: la igualdad ante la ley. Las directivas del Estado adquieren un sentido abstencionista. Esto quiere decir que entre menos intromisión y dirigismo estatal exista, habrá mayor libertad e igualdad normativa abstracta para el individuo. La seguridad de la libertad e igualdad se politiza en una actividad minimalista del Estado, valora más la libertad, formalira la igualdad y paraleliza el horizonte normativo en la legalidad. Las directivas cstatales se convierten en una política minimalista. La importancia del individuo sc jerarquiza frente a la colectividad. El Estado sc preocupa más por el indivicluo que por la persona y limita sus impulsos para la creación de instituciones de beneficio social. Sobra mencionar la aparición de las libertades fundamentales del individuo - propiedad, tránsito, domicilio, expresión y vida- así como de los procedimientos que garanticen un mínimo de tutela jurídica. Son cstas, en delinitiva, libertades para todos. Es el reconocimiento de la existencia de individuos iguales en libertad.

\section{3}

De la igualdad constitucional (I PARTE) 
El sistema estatal que se fundamenta en la liberalidad del individuo quiebra su legitimidad, cuando surgen series patológicas que dañan a las masas sociales. El clesempeño activo de la industria ocasiona inestabilidades por el descontento de los trabajadores. Aporte relevante son los hechos históricos de las guerras mundiales, la revolución soviética y la iconografía de los postulados marxianos.

\subsection{Discursiva anarquista de la igualdad formal}

Un anarquista como Proudhon ${ }^{17}$ identifica en la mala visión formal de la igualdad un estado de extrañeza y salvajismo. Ante los excesos del formalismo lcgal, exalta a la justicia siempre ciega, porque siempre es ignorante. La igualdad se ha vulgarizado. La equidad formal, que se distorsiona en el siglo XIX, es el absurdo del despotismo, un engaño para el pueblo, un abuso insensato e inmoral. Para Proudhon, la igualdad debería ser absoluta y no constituirse en objeto de transacción. La pérdida del sentido de la igualdad es la organización de la destrucción en la sociedad ${ }^{\prime k}$.

La igualdad formal, materializada en la propiedad, es una necesidad de vida que, sin considerar las necesidades del otro, es la imposición del engaño, la luerza y el pillaje, sentencia Proudhon. La igualdad es inseparable de la idea de personalidad, facultad del cuerpo y del espíritu, participación que santifica la libertad y, al ser negada, se convierte en una seductora imposibilidad y en una satánica mentira. La igualdad desuela los prejuicios y la incertidumbre. Explica los hechos sociales y ya adquirida no se pierde. Sanciona el egoísmo. Evita los corpes estímulos de abismos sin fondo que satisfacen únicamente al mal, al hombre ignorante y exacerban la discordia, la mentira y la guerra. La igualdad resucita, habilita, rejuvenece, restaura y refuerza la salvaguardia de las naciones turbadas y oscurecidas por la conciencia de los sabios. La igualdad frena la codicia, la ambición y dona posesiones ${ }^{19}$.

La igualdad descubre, formula, consagra y expresa la necesidad, reflexiona la buena le y contiene las previsiones. La igualdad estimula las necesidades inmedialas, saca beneficios del cambio, conserva los primitivos repartos, hace cue no se perjudique a las familias por injustas exclusiones, opulencia o miseria. No puede ser fugitiva ni infinita, pero es indispensable para no despojar a nadie cle sus bienes sin su voluntad. Institucionaliza la participación y la nivelación. No perjudica a nadie, concede la tolerancia, fomenta que no se alteren perjudicialmente cualidades, combina la sociedad con benevolencia para las minorías,

17. Creemos aplicables para el estudio de la igualdad las consideraciones que hace este autor sobre la propiedad. Cfr. Pierre Joseph Proudhon, ¿Qué es la propiedad? Orbis, Barcelona. Iª edición. 1975.

18. Op. cit., pág. 65 y ss.

19. Ídem. 
explota los beneficios del uno para el otro, evidencia la aproximación de valores, dirige y aproxima esfuerzos. Abre el campo de las diferencias de facultades, cue hacen la igualdad cle fortunas ${ }^{20}$.

\subsection{Socialización de la igualdad}

Los desajustes liberales hacen la creación de los Estados sociales ${ }^{21}$. Podríamos delinir a estos últimos como autoridades que ejercen medidas dirigistas de bienestar, mediante intervenciones activas. Es el esquema de los Estados maximalistas $2-$ Sin embargo, las intervenciones —especialmente, las del Ejecutivo- hacen que algunos Estados se transformen en dictaduras, Estados autoritarios o lascistas. El siguiente paso evolutivo detiene a los Estados en la democracia, que en cicrto modo devalúa el dirigismo, y poco a poco entra en una era de devaluación de la democracia, y poco a poco entra en una era de modernización de la burocracia, la cual, hoy en día, ha privalizado la mayor parte de las actividades que en la época del intervencionismo estuvieron en manos públicas. Ello hace que la igualdad sea modificada, no como una igualdad exigible solamente ante los poderes públicos, sino también ante los particulares.

Vćase la necesidad de reubicar las garantías y los derechos lundamentales lirente a los particulares, especialmente cuando éstos han absorbido funciones que correspondían al Estado. En El Salvador, para 1998, se han gestado procesos de privatización en el campo de la energía eléctrica, pensiones y telecomunicaciones $^{27}$. A la par surgen instituciones de control de tipo administrativo: las Superintendencias. Ello, en nuestra opinión, influye sobremanera para evitar los excesos. No obstante, la jurisdicción deberá tomar su propio camino para interlerir en posibles violaciones futuras a los derechos fundamentales cle los sujetos a quienes se brindan estos servicios.

20. Ibídem, pág. 79 y ss.

21. Hermann Heller, Gescumnelte Schrifien. Vol. II, Leiden, 1971. Citado por Ángel Garrorena Morales, en El Estado Español como Estado social y democrático de Derecho, Tecnos, 1991. $4^{a}$ reimpresión, pág. 34. Gösta Rehn, El futuro del Estado de Bienestar; en Revisra de Debate Político "El socialisino del futuro", número 3, Madrid, 1991, pág. 76.

22. El Estado de Bienestar supone una reforma del viejo Estado Liberal de Derecho, que pierde lo fundamental de su estructura jurídica política. Se traslada así, de un Estado mínimo a un Estado máximo. Éste último observa un gran potencial económico. como principal agente productor de servicios y materias primas. Clir. Andrćs de Blas y Ramón García Cotarello, Teoría del Estado. Universidad Nacional de Educación a Distancia. Facultad de Ciencias Políticas y Sociología. I Edición, 1998. Pág. 108 y ss.

23. El Centro de Inlormación, Documentación y Apoyo a la Investigación. CIDAI, de la UCA hace un análisis de la influencia de las privatizaciones en el artículo El Salvador en 1998: Política, economía y sociedad. Cfr. ECA, número 603, enero de 1999.

De la igualdad constilucional (I parie) 
La verticalidad de las relaciones jurídicas no es actualmente sólo materia correlacionada con el Estado, sino también con entidades privadas que han adquirido mayor poder que los Estados. La noción de derechos firente al Estado se legitimaba por la naturaleza dirigista. Ahora, la noción garantista de los derechos fundamentales tiene que verse no sólo frente al Estado, sino también ante sus concesionarios o actuales dueños de funciones que anteriormente eran dominio de la esfera pública.

\section{Estimativa ${ }^{24}$ de la igualdad}

\subsection{Libertad, justicia, equidad}

La igualdad posee un contenido genérico desde la moralidad constilucional. En primer lugar, lunciona como un desarrollo del valor de la dignidad de la persona humana ${ }^{25}$. Se lunda en la ética y en la idea de persona. La igualdad es un todo por encima de todo. Es la moralidad de la dignidad humana que se proyecta en los derechos fundamentales ${ }^{2 h}$. La justicia como valor fundamental suma en sus posesiones jurídicas un nuevo valor que se coloca con más cercanía de los derechos fundamentales al valor igualdad. Así, la igualdad adviene de la moralidad de la dignidad y se concretiza gracias al valor justicia ${ }^{27}$.

El Art. I Cn. supone la igualdad sin mencionarla expresamente. Debemos entender que el mandato de conseguir la igualdad social, la salud y la cultura encierran un mandato axiológico constitucional de conseguir la igualdad. En este sentido, la igualdad es un mandato general, axiológicamente determinado por nuestra Constitución, y que institucionaliza una obligación fundamental para los poderes constituidos. La igualdad, cuando se concreta en virtud de la administración de justicia, nos da la oportunidad de hablar de la realización de la igualdad como equidad.

24. Sentido axiológico o ético. Asunto que corresponde a los valores, fines del Estado y orden jurídico.

25. Puy se detiene en el discurso de la igualdad. Se trata de un discurso axiológico. normativo y postulativo. Ello es la visión del valor, principio y derecho fundamental. La propuesta de un político la convierte en valor: la de un normador, en principio. Lo anterior se traduce en propuestas genéricas que atenuan la superioridad de la clase dirigente. Cir. Francisco Puy. El derecho de igualdad en la Constitución española, en xı Jornadas de Estudio. El principio de igualdad en la Constitución española. pág. 135 y ss.

26. Bertrand Galindo. Tinetti y otros, Op. cit., pág. 795.

27. La dignidad connota lo merecido. Se trata de una cualidad de apropiación y no de medida. Establece el derecho y el deber. Conjuga lo común, lo igual, lo diverso y la adquisición sobre la base de la justicia. Cfr. Urbano Ferrer Santos, La igualdad como criterio determinante de lo justo, en XI Jornadas de estudio. El principio de igualdad en la Constitución espaiiola, pág. 132 y ss 
La jurisprudencia nacional de orden constitucional sostiene en la sentencia de amparo 167-97 del 25 de mayo de 1999 de la Sala de lo Constitucional, que las luchas históricas de los devenires humanos positivan la igualdad en función de una estructura jurisdiccional basada en la equidad y la justicia. Estas son las piedras angulaes de la jurisdicción que, ante las reyertas sociales, intentan conseguir lo más adecuado y el mejor tratamiento del individuo en una decisión. Amalgaman una interrelación solidaria "y conforman las directrices expresas o tácitas que todo juez debe utilizar al administrar justicia”. La opinión jurisprudencial se respalda en la filosofía italiana de Bobbio, para quien la igualdad "es un concepto emotivamente positivo, porque es algo que se desea, y está íntimamente vinculado con la justicia. En tal sentido, debe decirse que tal derecho se desplaza y anida, o debería hacerlo, en cada uno de los procesos jurisdiccionales. Debe dársele igualdad de oportunidades a cada una de las partes para el solo efecto de que puedan argüir o defender, en su caso, cada uno de los derechos que estima tutelables".

De relevancia es también el pronunciamiento en la sentencia de inconstitucionalidad del 18 de febrero de 1987. La sentencia declara inconstitucional la Ley del Impuesto para la Defensa de la Soberanía Nacional. Uno de sus fundamentos jurídicos relaciona el principio de equidad, que en materia tributaria se basa en la proporcionalidad e igualdad de la carga impositiva. Las contribuciones deben hacerse según las capacidades e ingresos. Los impuestos deben ser proporcionales a los ingresos, rentas o patrimonio, respetando el principio de la igualdad lirente a los impuestos, en el sentido que paguen impuestos iguales los sujetos con igual capacidad contributiva. La Sala considera que el impuesto arriba mencionado es excesivamente oneroso.

Un enfoque contemporáneo desde la filosofía constitucional completa el sentido de la igualdad con el valor libertad. Peces Barba, Eusebio Fernández y Rafael de Asís, al referirse a la igualdad, consideran que "estamos ante un valor que completa el sentido de la libertad ${ }^{28 " . ~ L o s ~ a u t o r e s ~ m e n c i o n a d o s ~ c o n v i e n e n ~ e n ~}$ citar la trasnformación que opera de la igualdad por intervención de la libertad. Entonces, cabe hablar de libertad igualitaria o libertad para todos. Ello implica que la igualdad debe ser interpretada desde la libertad, puesto que ésta es insuficiente sin igualdad. "La igualdad se legitima y se justifica si potencia la libertad, y se detiene o pierde sentido cuando puede limitarla o perjudicarla2y"

Conviene reseñar estas vinculaciones de la igualdad desde planos que critican la similitud y complementariedad que estos generan. Molinero distingue una

28. Gregorio Peces Barba, Eusebio Fernández y Rafael de Asís, Curso de Teoría del Derecho. Marcial Pons, Barcelona, I Edición, 1999. Pág. 337.

29. Ibídem, pág. 338.

De la Igualdad constifucional (I parte) 
serie de tensiones. En primer lugar, hace de la libertad una pertenencia personal e individual, mientras que la igualdad afecta a componentes humanos. La complejidad de la igualdad clasifica desigualdades naturales y artificiales. Las naturales devienen del origen, de la naturaleza — salud, fuerza, capacidad intelectual, sensibilidad moral y habilidades-. Las artificiales sobresalen en el poder, riqueza, educación o cultura. Claro está que las desigualdades sobrevenidas deben ser objeto de acción política que las reduzca o anule. Otra tensión radica en la ideología. Hay grupos que profesan y mantienen sus arreglos sociales. El liberalismo y el socialismo relacionan conflictos que no permiten una libertad o igualclad absolutas ${ }^{30}$.

La igualdad ligada a la libertad recibe un tratamiento similar por parte de Bidart Campos. La igualdad se liga a la libertad, con la negación de igualitarismos y clesigualaciones arbitrarias para la libertad a favor de ciertos individuos ${ }^{31}$. La igualdad, en su aspecto histórico, diferencia a las sociedades en que el Estado y el Derccho son las categorías generales, de aquellas que sólo utilizan esas categrorías en beneficio de un círculo reducido. El amo debe saber mandar, el esclavo tiene que saber hacer. La monarquía es el gobierno doméstico de uno solo; la política refiere la libertad e igualdad ${ }^{32}$.

\subsection{Del género humano}

Al tenor de las obligaciones fundamentales del Estado, consignadas en el artículo I Cn., no podemos olvidar la instrumentalización del pensamiento igualitario en beneficio de una noción personalista, fin primordial de la actividad estatal. En este sentido, con la igualdad se asienta el acercamiento del género humano por la vía de una unidad, que no puede diferenciar sino en lo necesario y racional. La búsqueda insiste en el logro de una unidad de satisfacción jurídica, de tal manera que ni la raza, ni el credo, ni las condiciones personales tampoco sean lormas de contribución al fraccionamiento que la sociedad no desea. El principio de igualdad en nuestra Constitución posee un abordaje genérico y toma una variedad de rumbos constitucionales. Uno de ellos es el señalado en la sentencia cle habeas corpus del 30 de mayo de 1996, en el que la Sala hace considerar el principio de igualdad en las manifestaciones concretas de los derechos humanos, lacultades e instituciones que acomodan la igualdad al momento histórico.

30. Marcelino Rodríguez Molinero, Tensión entre los derechos de igualdad y libertad, en XI Iornadas de Estudio: El Principio de la igualdad en la Constitución española. pág. 565 y ss.

31. Germán Bidart Campos, Filosofía del Derecho Constitucional. Edar. Buenos Aires. I“ edición. 1969. Pág. 243.

32. Javier Pérez Royo, Curso de Derecho Constitucional. Marcial Pons. Madrid, $1^{2}$ edición, 1969. Pág. 284. 


\section{La cláusula general de la igualdad}

\subsection{El derecho general de la igualdad}

La Constitución de 1983 identifica el derecho general de igualdad en la prescripción del Art. $3 \mathrm{Cn}$. Al respecto, establece que todas las personas son iguales ante la ley. Añade que, para el goce de derechos civiles, no podrán establecerse restricciones que se basen en diferencias de nacionalidad, raza o religión. Adjunta a la prescripción constitucional, se encuentra la prohibición de reconocer empleos y privilegios hereditarios.

\subsection{Derecho fundamental y principio superior del orden constitucional}

Podemos sostener que la cláusula general de igualdad es un derecho fundamental. Aunque algunos autores negativizan dicho carácter, Basile asevera que es un modo objetivo de ser en la ley y añade que no es un derecho fundamental. En opinión de Galvez, la igualdad es sólo un presupuesto necesario para la efectividad de los derechos y libertades ${ }^{13}$. La Corte Europea de Derechos Humanos circunscribe la igualdad a una garantía para la defensa de los derechos que protege la Convención, y no configura un derecho lundamental o principio. Los argumentos se recogen por el rc español en sus primeros años de funcionamiento, negando que constituye un derecho subjetivo autónomo. Este criterio se encuentra evidencia(lo en la STC 22/1981 y en la 27/1981. Posteriormente, su jurisprudencia decae en la calilicación negativa del derecho fundamental de la igualdad y hacen afirmaciones jurisprudenciales de validez. La STC 49/1982 refiere la igualdad como clerecho suhjetivo a obtener un trato igual; la STC/75 1983 asimila de forma anćlog̣a el carácter de derecho subjetivo de los ciudadanos a evitar privilegios y clesigualdades discriminatorias ${ }^{3-1}$.

La fórmula se repite en las STC 2/1984, I42/1985, 162/1985, 166/1985, $87198639 / 1986 ; 41,58,121$ y 125/1986; y en la 114/1987. Todas ellas podrían describirse como insistencias jurisprudenciales de la consagración constitucional yuc hace de la igualdad un derecho fundamental. Añaden algunas dilerenciacioness de contenido, así como objetivaciones de tratos justificados y razonables, según la linalidad; incluyen la igualdad ante la ley y en la aplicación de la misma. También comprenden la naturaleza del imperativo constitucional. Por otra parte, impiden diferencias arbitrarias, así como equiparan y compara la protección de hienes y valores constitucionales. Otra característica que poseen es que descuhren vulneraciones presuntas y correlacionan infracciones constitucionales a la igualdad con las vulneraciones a la tutela jurídica. Describen posibles violacio-

33. Francisco Puy. El derecho de igualdad en la Constitución Española. pág. 139.

34. Ibielem. pág. 143.

De la igualdad constitucional (I PARTE) 
nes del legislador en la creación normativa. Llama la atención la dispensa de un mismo trato en situaciones equiparables, en que la finalidad de la norma cuestionada no tiene justificación objetiva y razonable ${ }^{35}$.

Nuestra creencia se adhiere más a la posición de la igualdad como derecho fundamental, en vista de que el constituyente salvadoreño la incorpora en el apartado del Título II, referente a los derechos fundamentales ${ }^{36}$. Nos parece que la Constiıución salvadoreña incorpora los elementos definitorios que puedan considerarlo como derecho fundamental, debido a que es factible concebirlo como un mandato con un ámbito normativo propio. Sin embargo, no deben perderse de vista las generalidades que incorpora su contenido.

Royo y Lorca Navarrete ${ }^{37}$ comparten la naturaleza de la igualdad como derecho fundamental y subjetivo ${ }^{3 x}$. Peces Barba reitera esta idea, al postular los derechos de igualdad como derechos subjetivos de los ciudadanos y concibe a éstos como titulares de los primeros. Además, considera que los derechos de igualdad son verdaderos derechos de crédito ante el Estado y los poderes públicos. La igualdad, como derecho subjetivo de los ciudadanos para obtener un trato análogo. está concebida también por Cano-Mata. Por su parte, Fraga —redactor de la Constitución española de 1978- dice que la igualdad es el derecho de todo hombre a ser tratado como tal. Piñeiro y Fernández alegan un derecho de trato igual: lo conciben como objeto de protección de la misma manera que el resto de los derechos fundamentales, por su plena naturaleza y no por asimilación al orden jurídi-

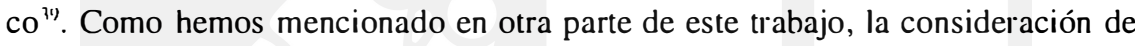
derecho fundamental comparte un aspecto estimativo, y naturaliza también el ámbito normativo de los principios. Más adelante, acudiremos a Puy para dar una explicación sobre la naturaleza mixta del derecho fundamental. Por el momento, observaremos otras posiciones que unifican la igualdad como principio.

\subsection{El principio}

Una parte de la doctrina enfoca la igualdad desde otro punto de vista: la naturaleza fundamental de un derecho. Se destaca que el derecho en cuestión es algo más

35. Ibiclem, pág. 143 y ss

36. Disentimos de la doctrina española que niega el carácter de derecho fundamental. puesto que sólo se reconoce el elemento de mandato, pero no el ámbito normativo propio. Cf́r. José María Pabón de Acuña. Problemática del principio constitucional de igualdad, en XI Jornadas de estudio. El principio de igualdad en la Constitución espaiñola, pág. 26.

37. La idea de Navarrete está en Francisco Puy. op .cit., pág. 40. Consideramos que su opinión recoge la literalidad de la Constitución y la significación de un derecho fundamental.

38. Javier Pérez Royo, op. cit., pág. 244.

39. Francisco Puy, op.cit., pág. 1.39 y ss. 
que un derecho fundamental: la naturaleza de ser un principio informador del ejercicio de los derechos fundamentales. La igualdad es, entonces, una exigencia básica para el ejercicio de los derechos fundamentales. Bilbeny comparte el criterio de colocar a la igualdad en el rango de principio ${ }^{4()}$. Por su parte, Cerrolaza lo proyecta en la aplicación para las comunidades autónomas de España ${ }^{41}$. Suay Rincón destaca que se trata de un valor y un principio normativo únicamente. En opinión de Ignacio Martínez, la igualdad es un elemento estructural de todo derecho; es un valor o principi recortado epistemológicamente. Ollero, terciando en la argumentación, piensa la igualdad como principio jurídico de vinculatoriedad inmediata. Finalmente, para Martínez la igualdad es un mediador de complejidad, que genera selecciones y conecta realidades, por lo que sugiere, en la rama de las conveniencias, prescindir de la referencia del derecho subjetivo ${ }^{42}$.

\subsection{Derechos-principio-valor}

Las meditaciones de la naturaleza de la iguaidad encuentran posiciones mixtas - por ejemplo, las de Pérez Luño y las de Francisco Puy - La animosidad de Puy recoge la igualdad como derecho fundamental, "para no lastrar con un suspenso perturbador, ni expectativas ilusorias en sus razonamientos". Este autor deriva tres dimensiones en la igualdad: primero, en el discurso axiológico, es un valor; en el discurso normativo, es un principio y en el postulativo, un derecho fundamental ${ }^{43}$.

Las investigaciones de Puy resumen del lado normativo de la igualdad las siguientes conclusiones. Primero, identifica la ineludible vinculación de la igualdad como principio y derecho fundamental. Los enunciados del principio de igualdad traducen las expresiones técnicas más usuales, que significan: nivelación de los inferiores al ras de los superiores y trato para todos de la misma manera, sin discriminación. De paso, desecha las especulaciones según las cuales los contenidos de la igualdad se concretan a cada paso, y, asimismo, enfatiza que la igualdad no contiene un mandato indeterminado, pues su naturaleza corresponde a un derecho autónomo. De la formulación de los enunciados del principio de igualdad, se deducen las siguientes afirmaciones para el derecho fundamental de la igualdad: El derecho de atracción hacia niveles superiores y el trato de los

4(). Norbert Bilbeny, Igualdad y principio de solidaridad, en XI Jornadas de Estudio, pág. 54.

41. Las consideraciones del criterio se ven evaluadas en las STC 37/1981, del 16 de noviembre. 1/1982. del 28 de enero y 76/1983. Cfr. Antonio Cerraloza Gómez. El principio de igualdad de las Comunidades Autónomas a la luz de la jurisprudencia constitucional, en XI Jornadas de estudio, pág. 61.

42. Jesús Ignacio Martínez, El principo de igualdad y la producción de diferencias en el Derecho, en XI Jornadas de estudio, pág. 544 y ss.

4.3. Cfir. Francisco Puy, Op. cit., pág. 136.

De la igualdad constlluclonal (I parti) 
inferiores para que los superiores los adhieran a su propio nivel; el derecho de trato igual que se hace con los demás y el derecho a no ser discriminado ${ }^{44}$.

Una conclusión importante de Puy es la noción especulativa de un concepto científico-jurídico, mientras el principio de igualdad, regla,norma y proposición lógica es práctico. Adquiere sentido esta conclusión si diferenciamos el derecho a la igualdad en el discurso jurídico y la igualdad-valor en el discurso político. La propuesta política no hace un principio, sino un valor en la igualdad. El derecho de igualdad se convierte por el postulado de los abogados. La igualdad, sea entendida como valor o como principio en su estructura lógica, es general y para todos, y es el efecto de toda norma jurídica y valoración moral ${ }^{45}$

\subsection{Jurisprudencia}

La jurisprudencia constitucional nacional resalta la mixtura de principio-derecho fundamental en la igualdad; en ocasiones, lo configura como un derecho general, y la mayor parte de las veces hace radicar sus funciones como principio procesal. La sentencia de amparo 38-S-93 del 14 de enero de 1997 afirma: "La violación que aduce la quejosa se le ha conculcado, cual es el principio de igualdad consagrado en la Constitución en el artículo 3, en la parte que aquí interesa, éste es un derecho subjetivo que posee todo ciudadano a obtener un trato igual, que obliga y limita a los poderes públicos a respetarlo, y exige que los supuestos de hecho iguales sean tratados idénticamente en sus consecuencias jurídicas, abarcando también la igualdad en la aplicación de la ley, de manera que un órgano jurisdiccional no pueda, en casos sustancialmente iguales, modilicar arbitrariamente el sentido de sus resoluciones, salvo cuando su apartamiento de los precedentes posea una fundamentación suficiente y razonada. En los supuestos de decisiones desiguales, debidas a órganos plurales, corresponde a la jurisprudencia de los órganos jurisdiccionales establecer la necesaria uniformidad en aplicación de la ley, en pro de la seguridad jurídica". El tribunal desestima el amparo y la violación de la igualdad por el hecho de la posición ventajosa cle la impetrante, que gozaba de franquicias para la explotación de tiendas libres.

A veces, la jurisprudencia ha valorado el derecho general de igualdad; en el amparo 24-G-96 del 23 de septiembre de 1996, se considera que no es afectado como trato desigual por la construcción de un muro de parte de la autoridad municipal. En los amparos 1-C-95 del $1^{\circ}$ de septiembre de 1996 y el 5-D-94, del 17 de encro de 1997, se vincula la igualdad a principios procesales y como principio natural del proceso junto a la garantía de audiencia. La función en el proceso de la igualdad-principio se menciona en la sentencia de amparo 3-H-93 del 29 de

44. Francisco Puy, Op. cit., pág. 136.

45. La mixtura, valor. principio. derecho fundamental, es compartida por Pérez Luño. Clir. Francisco Puy, Op. cit., pp. 137-139. 
mayo cle 1995, que contrae el principio de igualdad a una función de equilibrio procesal. La protección de los menores ha sido considerada en el amparo I-C-94 (lel 29 de septiembre de 1995, que contrae el principio de igualdad a una función (lc ecjuilibrio procesal. La protección de los menores ha sido considerada en el amparo I-C-94 del 29 de septiembre de 1995, que reconoce la mixtura del principio de igualdad del Art. $36 \mathrm{Cn}$., que obliga a no discriminar a los hijos nacidos (lentro o luera del matrimonio. Esto último se fundamenta en el derecho de igualdlacl consignado en el Art. $3 \mathrm{Cn} .{ }^{4 h}$. Pueden hallarse datos interesantes en el amparo 24-G-95 del 15 de agosto de 1995, que desestima el reclamo del derecho de igualclad para acceder a empleos públicos, puesto que no traduce un derecho a reclamar acceso a la Administración Pública. El documento aclara que opera sólo en la vertientc política como acceso a funciones públicas. En general, la jurisprudencia hal entrelazado la igualdad con derechos procesales, vinculados al emplazamiento, (lchido proceso, audiencia, contradicción y derecho a desvirtuar las incriminaciones.

En la sentencia de habeas corpus 15-M-94//6-M-95 del 17 de julio de 1995, la igualdad sirve para reivindicar la autonomía de las normas sistematizadas según matcria. "Por otro lado, el derecho procesal es una rama autónoma de la cnciclopedia jurídica que no se supedita o condiciona a otra disciplina, encontrán(lose, entonces, ambas ramas, en una situación de igualdad cuyas normativas conlicnen sus propias instituciones y sus propias reglas, por lo que no cabe confundir y mucho menos resolver situaciones de un derecho con reglas de otro". En el habeas corpus 1-B-95 del 13 de febrero de 1996, denomina el principio de igualdad como vinculante para todos los operadores jurídicos.

\subsection{Entrecruzamientos y resistencias}

Las generalidades del contenido del derecho general de igualdad no deben perder de vista ciertas imbricaciones. Primero, como derecho de interceptación, en cuanto alude a un entrecruzamiento con el resto de los derechos fundamentalcs. Este es un sentido del término que dificulta el pensamiento de violación de la igualdad que no comporte simultáneamente la violación de otro derecho. Por cllo, la igualdad no se viola en abstracto, sino en concreto ${ }^{47}$.

46. La sentencia deja clara la no discriminación por razones de nacimiento. Como señala Ballager, es meritoria la equiparación absoluta de los hijos en materia de filiación, haciendo desaparecer la profusidad vergonzosa que conllevaba una serie de adjetivos para los hijos nacidos fuera del matrimonio. Cfr. María Luisa Ballager Castejón, La aplicación judicial del principio de igualdad, en XI Jornadas de Estudio, pág. 297 y ss. El Tribunal Europeo, el 13 de junio de 1979, había considerado de igual forma, en el caso Marckx, que, a pesar de la perturbación de la tranquilidad de la vida familiar, la legislación belga violaba la igualdad al impedir el derecho de herencia y alimentos a hijos ilegítimos.

47. Luis López Guerra y otros. Derecho constitucional. El ordenamiento constitucional y' deberes de los ciudadanos. Pág. 29 y ss.

De la igualdad constllucional (I PARTE) 
Segundo, hay derechos que resisten de manera cspecial la prueba de la igual(lad ${ }^{\text {tx}}$ : la tutela judicial. Ia libertad religiosa y' la sindical. En la tutela judicial. el juicio de constitucionalidad se reserva a reconocer o no la lesión. En los privilcgios procesales, coloca al ante juicio para exigir responsabilidades a magistrados sobre la estimativa del no cierre del paso a la acción penal por motivos personales clel cucrellado. La igualdad en las resoluciones judiciales suma el deber de congruencia" con los precedentes, restricción de sentencias dispares. En la libertad religiosa, la igualdad inhibe la diferencia cle trato por cl hecho religioso. El Estaclo está coaccionado por un congelamiento activo, que implica la abstención de penetración so pena de ilicitud. En la libertad sindical, la igualdad implica la prohibición de un trato diferencial que no sca objetivo".

La (lescripción del contenido normativo para Puy relleja. describe y mentaliza una estructura que rechaza la distinciones odiosas, selccciona el conjunto de (laños, desventajas y males, así como las mutilaciones y marginaciones. Asimismo, olirece oportunidades para el ejercicio cle todos los (lerechos, las cuales son aprovechadas por todos los miembros del grupo social ${ }^{51}$.

\section{Igualdad formal}

\subsection{Dualidad de expresión}

La igualdad suele presentarse desde diferentes perspectivas. La primera de ellas conuerda en reconocer el engendro revolucionario de la igualdad formal. Los emblemas industriales, las guerras mundiales, la realidad profética maltusiana y la complejidad de las relaciones sociales estimarán que las ideas distributivas e inclusivas trastoquen las situaciones de los desposeídos o marginados, ya sea en lo político, en lo social, o en sus riquezas. Cabe así hablar de la igualdad material.

\subsection{La formalidad}

Por de pronto, nos dedicaremos a las facetas formalistas en la igualdad. La igualdad formal expresa el máximo de igualdad ante la ley. En este apartado nos dedicaremos a sus generalidades. En una sección posterior hablaremos de forma precisa sobre los deberes del legislador. El punto de partida de la igualdad formal es que todas las personas -y los grupos e instituciones que estas crean- son sujetos de derechos. Este es un punto de partida que se aleja de las visiones que

48. Presentamos la visión del Tribunal Constitucional Español.

49. La congruencia se mide también por la relación entre los supuestos de hecho y la linalidad. No hay congruencia en sujetar el derecho a pensión a la buena conducta. (STC 114/87). Ibidem, p. 167.

50. Referimos al lector a José María Pabón de Acuña, Op. cit., p. 29 y ss.

51. Cfi. Francisco Puy. Op. cit., p. 137 y ss. 
negaron la calidad de sujetos de derechos a los esclavos, o que aceptaron dicha calidad para las cosas o animales —recuérdense los procesos para las ratas responsables de epidemias de cólera en la Edad Media ${ }^{52}$ - La igualdad jurídica no debe ser conlundida con el comportamiento de una igualdad material o igualdad real y electiva. En delinitiva, un acercamiento a la dimensión esencial históricamenic diseñada para la igualdad es la superación cle la idea del privilegio, y cl asentamiento "de un derecho lormado por normas jurídicas generales dirigidas a un abstracto homo juriclicus, que es el hombre y el ciudadano"?

La igualdad ante la ley se estima en el Art. $52 \mathrm{CC}^{54}$, que considera persona a lodo individuo de la especie humana, sin distinción de edad, estirpe o condición. El inciso linal del Art. I Cn., relorma el principio civilista que considera el principio de existencia de la persona, y determina que se es persona desde la concepción. El Art. 55 CC no reconoce diferencias en el goce de derechos civiles entre el extranjero y el nacional, afïrmación que relativizaremos más adelante. Por su parte, el Art. $28 \mathrm{Cn}$., extiende los benelícios de la no extradición, en ningún caso, para los nacionales y la no extradición de extranjeros por delitos políticos, aunque resulten en consecuencia delitos comunes. El Art. $96 \mathrm{Cn}$. obliga a los cxtranjeros, desde que ingresan al país, a respetar a las autoridades y a someterse a las leyes nacionales. El Art. $98 \mathrm{Cn}$. prohibe reclamos indeminizatorios de salvadoreños o extranjeros por daños y perjuicios que les ocasionen las facciones ${ }^{55}$, pero pueden hacerlo contra los funcionarios culpables. Por otro lado. el Art. $3 \mathrm{Cn}$. prescribe que todas las personas son iguales ante la ley, sin distinción de raza, credo o nacionalidad. y prohibe reconocer empleos y privilegios hereditarios. El Art. 4 considera libres a todas las personas y prohibe la esclavitud.

\subsection{Leyes iguales e igualdad relativa}

Una primera aproximación a este tema podría venir de esta afirmación: todos los habitantes están sujetos a las mismas leyes. Pero esta aseveración contrasta con las diferencias de tratamientos de nacionales y extranjeros, menores y adultos, por lo cual no debe observarse como principio absoluto, sino relativo ${ }^{56}$. Zarine aclara que la propuesta constitucional de la igualdad no es absoluta, sino relativa, propiciada por una legislación tendiente a la protección, en lo posible, de las desigualdades naturales ${ }^{57}$. La legalidad constitucional incorpora en este sentido

52. Gregorio Peces Barba et al.. Op. cit., pág. 338.

53. Ibiclem.

54. Abreviatura de Código Civil

55. Se entiende como grupos que ocasionan daños, por ejemplo: manifestantes, asociaciones o personas que. rcunidas, extreman sus reclamaciones con violencia.

56. Adollo Gabino Ziulu, Derecho constitucional Tomo I. Principios y derechos constitucionciles. Depalma, Buenos Aires. primera edición. 1997, pág. 255.

57. Helio Juan Zorini, Derecho constitucional. Astrea-Depalma. Buenos Aires. $1^{\mathrm{a}}$ edición. 1992. Pág. 385.

De la igualdad constitucional (I PARTE) 
diversas prescripciones. En materia de extranjeros, el Art. 99 Cn. prohibe la vía diplomática para que los extranjeros resuelvan sus confliclos, salvo cuando se han agotado las vías judiciales o se les ha denegado justicia - lo cual no debe entenderse como fallo desfavorable- El Art. $100 \mathrm{Cn}$. sujeta a los extranjeros a una ley especial - la Ley de Extranjería-. El texıo del Art. 109 Cn. condiciona la adquisición de bienes rústicos al principio de reciprocidad internacional. El Art. $115 \mathrm{Cn}$. señala que el comercio, la industria y la prestación de servicios en pequeño son patrimonio de los salvadoreños.

El artículo 71 de la Constitución, así como los que le siguen, conceden derechos políticos a los ciudadanos salvadoreños, pero no proceden de igual forma con los extranjeros. El artículo $126 \mathrm{Cn}$., por ejemplo, establece que una persona deberá tener la condición de salvadoreño por nacimiento para ostentar la calidad de diputado. Similar requerimiento se hace en el Art. 151 Cn. para ser Presidente de la República; en el Art. 196, para ocupar una magistratura en la Corte Suprema de Justicia, y en los artículos 179 y 180 para ser Juez de Primera Instancia o Juez de Paz. Por otro lado, el Art. 91 sanciona con la pérdida de residencia en el territorio nacional a los extranjeros que participen directa o indirectamente en política. Finalmente, el Art. 60 obliga a que la historia nacional y la Constitución sean enseñadas exclusivamente por profesores salvadoreños.

Las diferencias de trato para los extranjeros se establecen en la sentencia 107/1984, del 23 de noviembre de 1984, en la jurisprudencia constitucional española. La sentencia señala que la diferencia de trato no sólo puede considerar el artículo único del derecho a la igualdad, sino que debe tomar en cuenta otros preceptos constitucionales. Deben hacerse consideraciones que relacionen esta legislación con los tratados. El principio constitucional de igualdad sólo se extiende en la medida que los derechos afectados sean imprescindibles para la garantía de dignidad humana ${ }^{5 x}$.

En materia de menores, el artículo 35 sujeta la conducta antisocial que constituye delito o falta a un régimen especial. El ordinal $10^{\circ}$ del artículo 38 prohibe el trabajo de menores de catorce años y de aquellos que sigan sometidos a enseñanza obligatoria. Prohibe, asimismo, el trabajo de menores de dieciocho años en labores nocturnas, insalubres o peligrosas, y limita la jornada de los menores de dieciséis años a seis horas diarias y treinta y cuatro semanales. La segunda parte del artículo 194 faculta al Procurador General de la República a velar por la defensa de los menores.

La igualdad formal condiciona que la ley sea general y se constituya en la garantía de igual capacidad jurídica ante los tribunales. Llorente destaca que la

58. María Concepción Aprell Lasagabaster. Principio de igualdad y' condición del extranjero. Posición del Tribunal Constitucional, en XI Jornadas de estudio, pp. 439 y ss. 
ley es igual para todos porque es general y abstracta. Esta idea estructura el sistema jurídico del Estado decimonónico. En ella, el legislador está limitado en virtud de las derivaciones de la estructura de igualdad ${ }^{59}$. La idea de igualdad ha ido imponiendo la búsqueda de ciertos límites para garantizarla. De ahí las exigencias de motivación, razonabilidad y no arbitrariedad en sus contenidos determinados por el legislador ordinario. Respecto de la administración, se ha popularizado la idea que sus actos no son definitivos y están sujetos a un posterior control jurisdiccional, lo cual hace que sus actos normativos no se decidan en menoscabo de los administrados.

En la jurisprudencia norteamericana la igualdad lormal evoluciona desde los primeros rechazos, que desvincularon a los jueces respecto de la declaración de (lerechos de la Constitución estadounidense ${ }^{(1)}$ - Barrow, 1833-, pasa por las distorsiones que sufre la decimocuarta Enmienda, cuando el Supremo justifica la segregación racial por medio de la doctrina "Separados pero iguales" — Plesy, 1896- La lucha igualitaria frente a la ley es cuestionada de nuevo con la opinión de dejar sin sanción la discriminación proveniente de una ley de Gobierno Federal. En el caso Bolling, de 1954, el Supremo norteamericano dice que el Gobierno Federal debe proveer un procedimiento legal que garantice la libertad y la igualdad.

En Europa, la igualdad formal retoma su debido protagonismo con la formación de órganos de control constitucional. En 1931, aparece el Tribunal de Garantías de la Constitución española; el Tribunal de la Constitución austríaca surge en 1920. El control de constitucionalidad de las leyes se introduce en forma delinitiva en la Constitución alemana de 1949, y en la italiana, en 1947.

59. Francisco Rubio Llorente. La igualdad en la jurisprudencia del Tribunal Constirucional. Inrroducción. En XI.lornadas de Esudio, pág. 699.

6(). Una explicación de este lenómeno puede deberse a lo que estudia Borrajo respecto de las competencias lederales en la constitución de Eslados Unidos. Cáda uno de los cincuenta Estados liene su propia Constitución aprobada autónomamente sin intervención de las autoridades lederales. La Constitución de Estados Unidos sólo regula a Estados Unidos. En el manojo de prohibiciones aplicables a los Estados. la única limitación está en la lorma republicana de gobierno; garantía guardada políticamente, y no por los tribunales judiciales. Los derechos fundamentales que introducen posteriormente las enmiendas se aplican por parte de los tres poderes federales, pero no alteran el texto lederal. Domina la tesis del truismo, que permite conservar, en potestades tasadas y limiladas, un conjunto limitado de competencias. Los Estados conservan todo aquello que no ha sido entregado. Cfr. Ignacio Borrajo Iniesta. El estado de las Autonomias a la lir: de la experiencia federal de los Estados Unidos. Centro de Estudios Constitucionales. Madrid. l“ edición. 1988. Pág. 34 y ss. 